\title{
A REVIEW ON BIOGENIC PROPERTIES OF STEM BARK OF TERMINALIA ARJUNA: AN UPDATE
}

\author{
DINANATH GAIKWAD*, NAMDEO JADHAV
}

Department of Pharmaceutics, Bharati Vidyapeeth College of Pharmacy, Kolhapur - 416 013, Maharashtra, India. Email: gdinanath@gmail.com

Received: 02 April 2018, Revised and Accepted: 05 May 2018

\begin{abstract}
The traditional and alternative systems of medicine have been resulting more than $85 \%$ of the drugs from a plant source. Terminalia arjuna (T. arjuna) stem bark contain glycosides, ample quantities of flavonoids, tannins, and minerals. Flavonoids have been identified to exert antioxidant, antiinflammatory, and lipid-lowering effects while glycosides are cardiotonic, thus making T. arjuna bark inimitable. In this review, an attempt has been made to discuss various aspects of its ethnomedical, phytochemical, pharmacological, and clinical relevance to various ailments condition. Available data from PubMed, Science Direct, and Web of Science were reviewed. Review articles, case reports, and clinical studies were included. Ultimately, after the elimination of repetitive information, 60 articles were identified. Most of the studies, both experimental and clinical, have suggested that T. arjuna bark possesses anti-ischemic, antioxidant, and hypolipidemic activity. Its useful phytoconstituents are triterpenoids, flavonoids, glycosides, tannins, phenolics, and arjunolic acid. Experimental studies have revealed that T. arjuna bark exerting significant cardioprotective and as potent antioxidant activity. So far, no serious side effects have been reported with T. arjuna bark therapy. However, its long-term safety still remains to be elucidated. T. arjuna bark has been found quite useful as cardioprotective agent. The present comprehensive update review is, therefore, an effort to give detailed information on T. arjuna stem bark for overall management of several ailments.
\end{abstract}

Keywords: Antioxidant, Cardioprotective, Flavonoids, Terminalia arjuna bark.

(C) 2018 The Authors. Published by Innovare Academic Sciences Pvt Ltd. This is an open access article under the CC BY license (http://creativecommons. org/licenses/by/4. 0/) DOI: http://dx.doi.org/10.22159/ajpcr.2018.v11i8.26384

\section{INTRODUCTION}

The traditional and alternative systems of medicine have been resulting more than $85 \%$ of the drugs from a plant source. Plants have been one of the important sources of medicines since the beginning of human civilization. Medicinal plants use well ingrained and is a part of culture and heritage. Therefore, the valuation of tradition treatment is important [1]. However, it pays more attention due to their efficacy, abundant availability, inflated cost of modern medicines, and cultural predilections [2]. The practice of medicinal plant either as a single drug or in combination is growing in the health care of human being. Globally, the use of bark, seeds, root, berries, leaves, or flowers of the plant for the medicinal purpose has demanded by a substantial number of people due to the perception that they are less toxic than mainstream drugs. Thus, there is an incentive to use them to treat various diseases [3]. In compliance to demands for the addition of compounds from therapeutic plants in treatments, manufacturers have had to ensure the addition of superior extracts using ideal standardization methods [4]. Several reports have documented that the plants by natural way accumulates and synthesis secondary metabolites such as glycosides, alkaloids, tannins, and volatile oils and contain vitamins and minerals, possess medicinal properties [5]. However, the correct therapeutic identification of the several plant drug materials mentioned in the traditional system of medicine has remained a problem till today. Hence, there is an urgent need to undertake based on scientific parameters such as ethnomedical, phytochemical, and phytopharmacological studies. Terminalia arjuna (Roxb.) weight and Arn., (T. arjuna) commonly known as "Arjuna," especially bark part has been used in heart failure, ischemia, cardiomyopathy, atherosclerosis, myocardium necrosis, blood diseases, anemia, venereal, and viral disease. It is used in the treatment of fractures, ulcers, and hepatic and showed hypocholesterolemic, antibacterial, antimicrobial, antitumoral, antioxidant, antiallergic and antifeedant, antifertility, and anti-HIV activities. T. arjuna stem bark contains glycosides, ample quantities of flavonoids, tannins, and minerals. Flavonoids have been identified to exert antioxidant, anti-inflammatory, and lipid-lowering effects while glycosides are cardiotonic [6-10].
As there is no revealing potent plant part to be explored till date, time is ripe for evaluating T. arjuna stem bark in the overall management of several ailments. In the current study, a wide range of ethnomedical, phytochemical, pharmacological, clinical and toxicity aspects of stem bark of T. arjuna was studied. For this purpose, databases such as PubMed, Science Direct, and Web of Science were reviewed. Review articles, case reports, and clinical studies were included. Ultimately, after the elimination of repetitive information, 60 articles were identified.

T. arjuna (Roxb.) Wight and Arn. is a deciduous and evergreen tree, standing $20-30 \mathrm{~m}$ above ground level, which is belongs to Combretaceae family comprising nearly 200 species distributed around the world. Nearly, 24 species of Terminalia have been reported from various parts of India. T. arjuna is about 60-80 feet in height, buttressed trunk and horizontally spreading crown and drooping branches distributed in India, Burma, Mauritius, and Sri Lanka [11]. Stem bark of $T$. arjuna is simple, smooth and pinkish-gray in color in external view. Internally, the bark is soft and reddish in color. T. arjuna bark is said to be sweet, acrid, cooling and heating, aphrodisiac, expectorant, tonic, styptic, antidysenteric, purgative, and laxative. Its use has been promoted in urinary discharge, strangury, leukoderma, anemia, hyperhidrosis, asthma, and tumors. The practice of bark powder as an astringent and diuretic included in the works of Charaka [12]. The conventional method of its administration was to prepare an alcoholic decoction of its bark stem (asava) or give it along with clarified butter (ghrita) or along with boiled milk (kshirpak) [13,14].

The chemical constituents of stem bark of T. arjuna are shown in Table 1.

The bark of T. arjuna was first reported 34\% ash content consisting entirely of pure calcium carbonate. The aqueous extract revealed $23 \%$ calcium salts and $16 \%$ tannins, whereas the alcoholic extract limited to coloring matter and tannins. Later, bark showed evidence of sugar, tannins (12\%), coloring matter, a glycoside, and carbonates of calcium, sodium and traces of chloride of alkali metals. Afterward, the presence of an alkaloid as well as a glycoside was confirmed [34]. Isolation of glycoside resulted into organic acid with a high melting point, a phytosterol, $12 \%$ 
tannins consisting largely of pyrocatechol tannins, huge quantities of calcium and minor amounts of aluminum and magnesium salts, coloring matter, and sugar [7,35]. Primarily an oleanane triterpenoid named, arjunin, and a lactone, arjunetin was isolated from the benzene and alcoholic extracts of its bark, respectively. Existence of arjunic acid and arjungenin in the bark stem was subsequently confirmed and two more glucosides, namely arjunglucoside I and arjunglucoside II were reported $[16,36]$. Later, a triterpene carboxylic acid, terminic acid, and arjunoside III and arjunoside IV were isolated from the ethyl acetate extract of its root $[37,38]$. Terminic acid was also isolated from the $n$-hexane extract of T. arjuna heartwood along with beta-sitosterol. It was also the initial study of the occurrence of a lupane derivative in any Terminalia species [17]. Recently another new glucoside named as $2 \alpha, 19 \alpha$-dihydroxy-3-oxoolean-12-en28-oic acid 28-O- $\beta$-d-glucopyranoside has been detected from its root [39]. T. arjuna bark contains a very high level of flavonoids compared to other commonly used plant item. Flavonoids perceived from its bark are, namely arjunolone, flavones, baicalein, quercetin, kaempferol, and pelargonidin. The chemically, arjunolone was established as 6,4-dihydroxy-7-methoxy flavone and that of baicalein as 5,6,7-trihydroxy flavone [21]. Recently a new flavonoid named luteolin has been isolated from 1- butanol extract of T. arjuna. Luteolin has been found to be antimutagenic and antibacterial. It inhibits the development of Gram-negative pathogen Neisseria gonorrhoeae with a minimum inhibitory concentration (IC) of 12.5-25 $\mu \mathrm{g} /$ disk. Its cancer cell growth inhibitory action is amplified by ethyl gallate and gallic acid [28]. About 15 types of tannins and related type of compounds have been isolated from its bark so far [32]. The bark also contains substantial amounts of magnesium (4000 $\mu \mathrm{g} / \mathrm{g})$, calcium $(3133 \mu \mathrm{g} / \mathrm{g})$, zinc $(119 \mu \mathrm{g} / \mathrm{g})$, copper $(19 \mu \mathrm{g} / \mathrm{g})$, and silica [10].

T. arjuna bark is having widespread therapeutic potential in most of the diseases mainly cardiovascular disorders. Scientific findings of T. arjuna bark through various preclinical and clinical studies are shown in Table 2.

Table 1: The chemical constituents of stem bark of T. arjuna

\begin{tabular}{|c|c|c|}
\hline Chemical type & Major chemical constituents & References \\
\hline \multirow[t]{6}{*}{ Triterpenoids } & Arjunin & Row et al. [15] \\
\hline & Arjunic acid & Row et al. [15] \\
\hline & Arjungenin & Honda et al. [16] \\
\hline & Terminic acid & Anjaneyulu and Prasad [17] \\
\hline & Terminoltin & Singh et al. [18] \\
\hline & Arjunolic acid & Singh et al. [19] \\
\hline \multirow[t]{4}{*}{ Ursane triterpenoids } & $2 \alpha, 3 \beta$-dihydroyurs-12,18-oic acid 28-O- $\beta$-D-glucopyranosyl ester & Wang et al. [20] \\
\hline & Qudranoside VIII & Wang et al. [20] \\
\hline & Kajiichigoside F1 & Wang et al. [20] \\
\hline & $\begin{array}{l}2 \alpha, 3 \beta, 23 \text {-trihydroxyurs-23-trihydroxyurs-12,19-dien-28-oic acid } \\
28-0 \text { - } \beta \text {-D-glucopyranosyl ester }\end{array}$ & Wang et al. [20] \\
\hline \multirow[t]{8}{*}{ Glycosides } & Arjunetin & Row et al. [15] \\
\hline & Arjunoside I, II & Honda et al. [16] \\
\hline & Arjunolone & Sharma et al. [21] \\
\hline & Arjunolitin & Tripathi et al. [22] \\
\hline & Olean-3 $\beta, 22 \beta$-diol-12-en-28 $\beta$-D-glucopyranosie-oic acid & Patnaik et al. [25] \\
\hline & Terminarjunoside I and II & Alam et al. [26] \\
\hline & Terminoside A & Ahmad et al. [27] \\
\hline & Termionic acid & Ahmad et al. [27] \\
\hline \multirow[t]{13}{*}{ Flavonoids and phenolics } & Arjunone & Sharma et al. [21] \\
\hline & Luteolin & Pettit et al. [28] \\
\hline & Baicalein & Anonymous [29] \\
\hline & Ethyl gallate & Anonymous [29] \\
\hline & Gallic acid & Anonymous [29] \\
\hline & Kaempferol & Anonymous [29] \\
\hline & Oligomeric proanthocyanidins & Anonymous [29] \\
\hline & Pelargonidin & Anonymous [29] \\
\hline & Quercetin & Anonymous [29] \\
\hline & $(+)$-catechin, $(+)$-gallocatechin and (-)-epigallocatechin & Saha et al. $[30]$ \\
\hline & Gallic acid, ellagic acid and its derivatives such as & Saha et al. [30] \\
\hline & 3-O-methyl-ellagic acid 4-O- $\beta$-D-xylopyranoside & \\
\hline & (-)-epicatechin & Wang et al. [20] \\
\hline \multirow[t]{8}{*}{ Tannins } & Pyrocatechols & Takahashi et al. [31] \\
\hline & Punicallin & Lin et al. [32] \\
\hline & Castalagin & Kuo et al. [33] \\
\hline & Casuariin & Kuo et al. [33] \\
\hline & Casuarinin & Kuo et al. [33] \\
\hline & Punicalagin & Kuo et al. [33] \\
\hline & Terchebulin & Kuo et al. [33] \\
\hline & Terflavin C & Kuo et al. [33] \\
\hline Minerals and trace elements & Calcium, magnesium, aluminum, zinc, copper, silica & Dwivedi and Udupa [10] \\
\hline Other compounds & $\beta$-Sitosterol & Anjaneyulu and Prasad [17] \\
\hline
\end{tabular}

T. arjuna: Terminalia arjuna 
The cardioprotective potential of T. arjuna stem bark on the molecular basis was assessed using cell cultures of human monocytic and human aortic endothelial cells. Inhibitory effect of alcoholic and aqueous extracts of T. arjuna stem bark was evaluated on human 3-hydroxy- 3-methylglutaryl coenzyme A reductase, lipoprotein lipase and lipid peroxidation in rat liver and heart homogenates [51].

Triterpenoids are principally responsible for cardiovascular properties. Alcoholic and aqueous bark extracts of T. arjuna, arjunic acid, arjunetin, and arjungenin were assessed for their potential to inhibit CYP3A4, CYP2D6, and CYP2C9 enzymes in human liver microsomes. Bark extract of T. arjuna showed effective inhibition of all three enzymes in human liver microsomes with $\mathrm{IC}_{50}$ values $<35 \mathrm{mg} / \mathrm{ml}$. Enzyme kinetics studies suggested that the extracts of T. arjuna exhibited rapidly reversible noncompetitive inhibition of all three enzymes in human liver microsomes. They proposed strongly that T. arjuna extracts significantly inhibit the activity of CYP3A4, CYP2D6, and CYP2C9 enzymes [52].

Dried pulverized bark of T. arjuna was given orally to Wistar albino rats $(120-150 \mathrm{~g})$ in two doses (500 and $750 \mathrm{mg} / \mathrm{kg}$ in $2 \%$ carboxymethyl cellulose), 6 days/week for 12 weeks. The determination of baseline changes in cardiac endogenous antioxidant compounds superoxide dismutase, reduced glutathione and catalase or the hearts were exposed to oxidative stress associated with in vitro ischemic-reperfusion injury. Significant increase in myocardial thiobarbituric acid reactive substance occurred in the vehicle-treated hearts subjected to in vitro ischemic-reperfusion injury. Hearts of rats were suggestively protected from oxidative stress when subjected to in vitro ischemic-reperfusion injury. The crude bark of T. arjuna augments endogenous antioxidant compounds of rat heart and disallowed oxidative stress associated with IRI of the heart [53].

In another study, antioxidative and antimicrobial properties have been explored for methanolic extract of T. arjuna bark. The antimicrobial activity exhibited that higher inhibition against Gram-negative bacteria than Gram-positive bacteria and showed promising antioxidant activity, as absorption of 2,2-diphenyl-1picrylhydrazyl (DPPH) radicals decreased in DPPH free radical scavenging assay. The methanol extract from the bark of T. arjuna showed medicinal as well as physiological activities. Methanol, ethanol, acetone, and aqueous both hot and cold extracts from the leaves and bark of T. arjuna were tried for their antimicrobial activity against Staphylococcus aureus, Acinetobacter sp., Proteus mirabilis, Escherichia coli, Pseudomonas aeruginosa, and Candida albicans, pathogens causing ear infections. Three organic solvents assessed acetonic leaf extract was found to be best against $S$. aureus. Organic bark extract exhibited almost equal inhibition of all tested Gram-negative bacteria except $P$. aeruginosa [54].

Table 2: Pharmacological studies on stem bark of T. arjuna

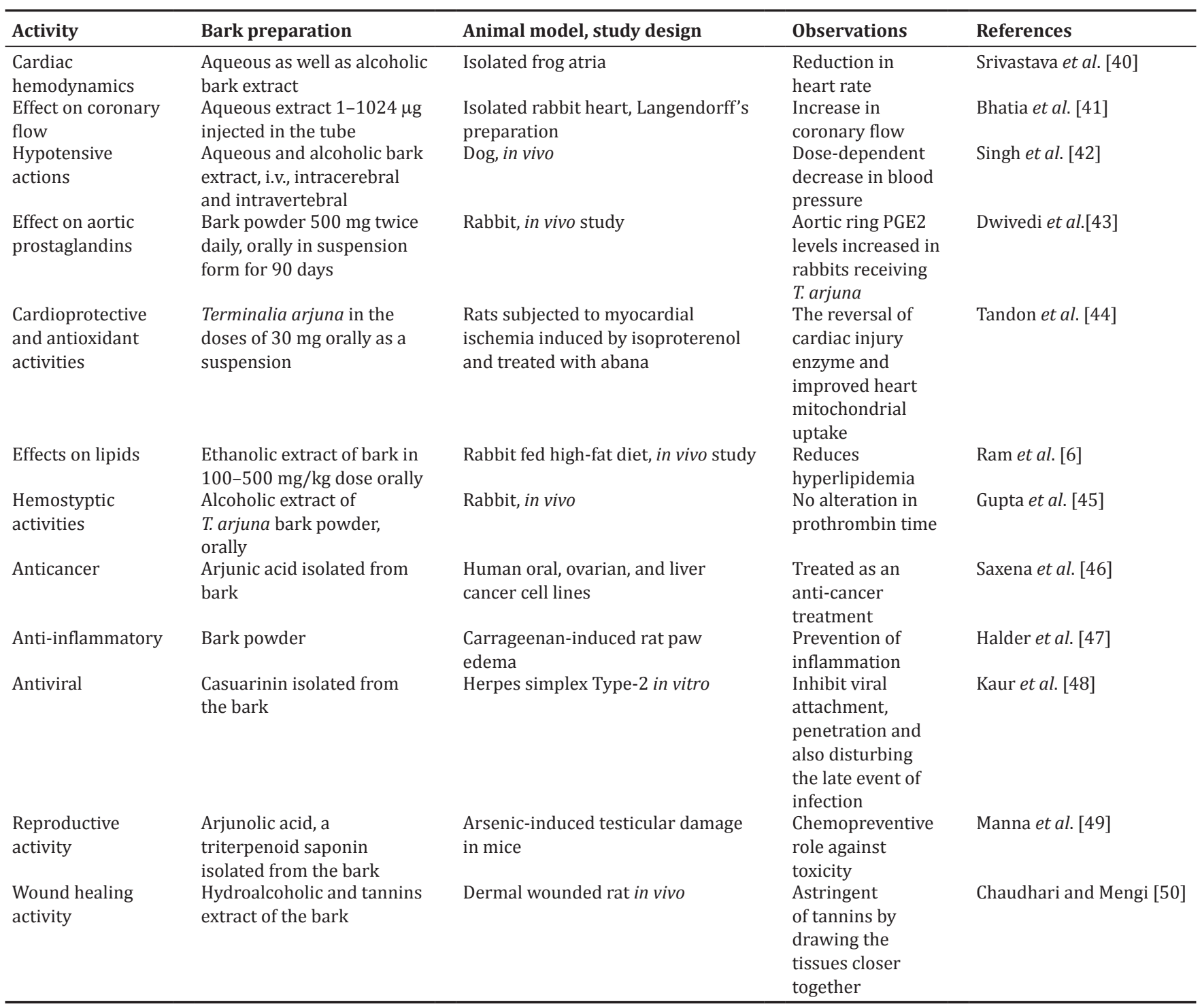

T. arjuna: Terminalia arjuna 
In a recent study, the therapeutic potential of $T$. arjuna on the inflammatory markers in subjects with stable coronary artery disease (CAD) was examined. In a placebo-controlled, randomized, and doubleblind study, 116 patients with a stable CAD who were on standard cardiac medications for more than 3 months were enrolled and received either placebo or $500 \mathrm{mg}$ of T. arjuna from Himalayan Herbal Healthcare, Bangalore, India, twice a day in addition to receiving the conventional treatment. A substantial reduction in serum triglycerides as well as in various inflammatory cytokines such as hsCRP, IL-18 $(\mathrm{p}<0.001)$, IL-6, and TNF-a $(\mathrm{p}<0.05)$ was noted at 3 months in patients who were on drug treatment [11].

A study was conducted to determine the improvement of endothelial dysfunction in smokers. 18 healthy male smokers (age 28.16 \pm 9.45 years) and an equal number of age-matched, non-smoker controls contributed to the study. The smokers were given T. arjuna $(500 \mathrm{mg}, 8 \mathrm{~h}$ ) or matching placebo randomly in a double-blind crossover design for 2 weeks each, followed by repetition of brachial artery reactivity studies to determine various parameters including flow-mediated dilation after each period. The flow-mediated dilation exhibited significant improvement from baseline values after T. arjuna therapy [55].

Aqueous bark extract of T. arjuna has shown its protecting capability to the membrane-bound enzymes and the enzymes of the metabolic pathway of anaerobic oxidation [56]. The administration of T. arjuna bark powder along with statins for 3 months to 30 patients with CAD resulted in a 16\% in low-density lipoprotein -cholesterol, $15 \%$ decrease in total cholesterol and $11 \%$ in triglycerides, confirming its immense potential to correct dyslipidemia in conjunction with statins [57]. This plant can be used as hepato-protecting due to the presence of various bioactive compounds such as phenolics, flavonoids, and tannins [58].

T. arjuna has been used in the dose between 1 and $2 \mathrm{~g} /$ day in different clinical studies and found that this is an optimum dose in the patient's particularly CAD. These doses have minor side effects such as headache, mild gastritis, and constipation. There were no reports in respects of hematological, hepatic, metabolic, and renal toxicity after more than 2 years of its administration [59].

Pretreatment with arjunolic acid from the T. arjuna bark successfully disallowed the cerebral I/R induced oxidative damage by its antioxidant potential and supplementation of arjunolic acid may be beneficial in stroke-prone population. Arjunolic acid from T.arjuna reduced sodium nitrite-induced cardiac damage in rats and reinstated the normal balance between pro- and anti-inflammatory cytokines [60].

\section{CONCLUSION}

Based on the existing literature evidence, the review reveals that T. arjuna stem bark is a very important therapeutically with its substantial number of phytochemical and pharmacological properties and contain medicinally important chemicals such as triterpenoids, flavonoids, glycosides, tannins, phenolics, and arjunolic acid. T. arjuna stem bark has been broadly used for the treatment of cardiovascular diseases, including heart diseases and related chest pain, high blood pressure, and high cholesterol. The effectiveness of T. arjuna stem bark as a cardioprotective and potent antioxidant has been sufficiently demonstrated in different experimental and clinical studies. However, continuous research progress on T. arjuna stem barkis very much needed in the regard of exact molecular mechanism, drug administration, drugdrug interactions, and toxicological studies. Further, a well-designed study to assess its toxicity from its long-term use is another urgency.

\section{AUTHOR'S CONTRIBUTION}

Both the authors were equally involved in the drafting, gathering information, and design of a framework of the manuscript.

\section{CONFLICTS OF INTEREST}

Nil.

\section{REFERENCES}

1. Heinrich M. Ethnobotany and its role in drug development. Phytother Res 2000;14:479-88

2. Tabuti JR, Lye KA, Dhillion SS. Traditional herbal drugs of Bulamogi, Uganda: Plants, use and administration. J Ethnopharmacol 2003;88:19-44.

3. Ayyanar M, Sankarasivaraman K, Ignacimuthu S. Traditional herbal medicines used for the treatment of diabetes among two major tribal groups in south Tamil Nadu, India. Ethnobot Leaf 2008;12:276-80.

4. Pashazanousi MB, Raeesi M, Shirali S. Chemical composition of the essential oil, antibacterial and antioxidant activities, total phenolic and flavonoid evaluation of various extracts from leaves and fruit peels of Citrus limon. Asian J Chem 2012;24:4331-4.

5. Hafiz FB, Towfique NM, Sen MK, Sima SN, Azhar BS, Rahman MM. A comprehensive ethno-pharmacological and phytochemical update review on medicinal plant of Terminalia arjuna Roxb. of bangladesh. Sch Acad J Pharm 2014:3:19-25.

6. Ram A, Lauria P, Gupta R, Kumar P, Sharma VN. Hypocholesterolaemic effects of Terminalia arjuna tree bark. J Ethnopharmacol 1997;55:165-69.

7. Bachaya HA, Iqbal Z, Khan MN, Jabbar A, Gilani AH, Din IU. In vitro and in vivo anthelmintic activity of Terminalia arjuna bark. Int J Agric Biol 2009;11:273-8.

8. Phanikumar G, Navya K, Ramya EM, Venkataramana M, Anand T, Anilakumar KR. DNA damage protecting and free radical scavenging properties of Terminalia arjuna bark in PC-12 cells and plasmid DNA. Free Radic Antioxid 2013;3:35-9.

9. Dwivedi S. Terminalia arjuna Wight and Arn.- a useful drug for cardiovascular disorders. J Ethnopharmacol 2007;114:114-29.

10. Dwivedi S, Udupa N. Terminaliaarjuna: Pharmacognosy, phytochemistry, pharmacology and clinical use a review. Fitoterapia 1989;60:413-20.

11. Kapoor D, Vijayvergiya R, Dhawan V. Terminalia arjuna in coronary artery disease: Ethnopharmacology, pre-clinical, clinical and safety evaluation. J Ethnopharmacol 2014;155:1029-45.

12. Acharya JT. The Charak Samhita. $3^{\text {rd }}$ ed. Bombay: The Nirnaya Sagar Press; 1941.

13. Nadkarni AK, Nadkarni KM. Indian Materia Medica. $1^{\text {st }}$ ed. Bombay: Popular Book Depot; 1954

14. Warrier PK, Nambiar VP, Ramankutty C. Indian Medicinal Plants- A Compendium of 500 Species. $1^{\text {st }}$ ed. Madras: Orient Longman Limited; 1996.

15. Row LR, Murty DS, Subbarao GS, Sastry CS, Rao KV. Chemical examination of Terminalia arjuna: Part-III- Isolation and structure determination of arjunetin from Terminalia arjuna, species. Indian $\mathrm{J}$ Chem 1970;8:772-5.

16. Honda T, Murae T, Tsuyuki T, Takahashi T, Sawai M. Arjungenin, arjunglucoside I and arjunglucoside II, a new triterpene and new triterpene-glucosides from Terminalia arjuna. Bull Chem Soc Jpn 1976;49:3213-8.

17. Anjaneyulu AS, Prasad AV. Structure of terminic acid, a dihydroxytriterpene carboxylic acid from Terminalia arjuna. Phytochemistry 1983;22:993-8.

18. Singh B, Singh VP, Pandey VB, Rucker G. A new triterpeneglycoside from Terminalia arjuna. Planta Med 1995;61:576-7.

19. Singh DV, Verma RK, Singh SC, Gupta MM. RP-LC determinationof oleane derivatives in Terminalia arjuna. J Pharm Biomed Anal 2002;28:447-52.

20. Wang W, Ali Z, Shen Y, Li X, Khan IA. Ursane triterpenoids from the bark of Terminalia arjuna. Fitoterapia 2010;81:480-4

21. Sharma PN, Shoeb A, Kapil RS, Popli SP. Arjunolone: A new flavones from stem bark of Terminalia arjuna. Indian J Chem 1982;21B:263-4.

22. Tripathi VK, Pandey VB, Udupa KN, Rucker G. Arjunolitin, a triterpene glycoside from Terminalia arjuna. Phytochemistry 1992;31:349-51.

23. Ali A, Kaur G, Hayat K, Ali M, Ather M. A novel naphthanolglycoside from Terminalia arjuna with antioxidant and nitricoxide inhibitory activities. Pharmazie 2003;58:932-4.

24. Wang W, Ali Z, Li XC, Shen Y, Khan IA. Triterpenoids from two Terminalia species. Planta Med 2010;76:1751-4.

25. Patnaik T, Dey RK, Gouda P. Isolation of triterpenoidglycoside from bark of Terminalia arjuna using chromatographic technique and investigation of pharmacological behavior upon muscle tissues. E J Chem 2007:4:474-9.

26. Alam MS, Kaur G, Ali A, Hamid H, Ali M, Athar M. Two new bioactive oleanane triterpene glycoside from Terminalia arjuna. Nat Prod Res 2008;22:1279-88.

27. Ahmad MU, Mullah KB, Norin T, Ulla JK. Terminoic acid, a new trihydroxytriterpene carboxylic acid from bark of Terminalia arjuna. 
Indian J Chem 1983;22:738-40.

28. Pettit GR, Hoard MS, Doubek DL, Schmidt JM, Pettit RK, Tackett LP, et al. Antineoplastic agents 338. The cancer cell growth inhibitory. Constituents of Terminalia arjuna (Combretaceae). J Ethnopharmacol 1996;53:57-63.

29. Anonymous. Terminalia arjuna. Altern Med Rev 1999;4:436-7.

30. Saha A, Pawar VM, Jayaraman S. Characterization of polyphenols in Terminalia arjuna bark extract. Indian J Pharm Sci 2012;74:339-47.

31. Takahashi SH, Tanaka H, Hano Y, Ito KT, Nomura T, Shigenobu K. Hypotensive effects in rats of hydrophilic extract from Terminalia arjuna containing tannin related compounds. Phytother Res 1997;11:424-7.

32. Lin TC, Chien SC, Chen HF, Hsu FL. Tannins and related compounds from Combretaceae plants. Chin Pharm J 2000;52:1-26.

33. Kuo PL, Hsu YL, Lin TC, Lin LT, Chang JK, Lin CC. Casuarinin from the bark of Terminalia arjuna induces apoptosis and cell cycle arrest in human breast adenocarcinoma MCF-7cells. Planta Med 2005; 71:237-43

34. Ghosh S. Annual report of the Calcutta School of Tropical Medicine. Calcutta: Institute of Hygiene and the Carmichel Hospital for Tropical Diseases; 1926.

35. Chopra RN, Ghosh S. Terminalia arjuna: Its chemistry, pharmacology and therapeutic action. Indian Med Gaz 1929;64:70-3

36. Honda T, Murae T, Tsuyuki T, Takahashi T. The structure of arjungen: A new sapogenin from Terminalia arjuna. Chem Pharm Bull 1976;24:178-80

37. Anjaneyulu AS, Prasad AV. Chemical examination of roots of Terminalia arjuna (Roxb.) Wight and Arnot. Part I. Characterisation of two new triterpenoid glycosides. Indian J Chem 1982;21:530-3.

38. Anjaneyulu AS, Prasad AV. Chemical examination of roots of Terminalia arjuna-the structure of arjunoside III and arjunoside IV, two new triterpenoid glycosides. Phytochemistry 1982;21:2057-60.

39. Choubey BK, Srivastava SK. Antifungal agents from Terminalia arjuna. Indian J Chem2001;40B:354-6.

40. Srivastava RD, Dwivedi S, Sreenivasan KK, Chandrashekha CN. Cardiovascular effects of Terminalia species of plants. Indian Drugs 1992;29:144-9.

41. Bhatia J, Bhattacharya SK, Mahajan P, Dwivedi S. Effect of Terminalia arjuna on coronary flow-an experimental study (Abstract). Indian J Pharmacol 1998;30:118.

42. Singh N, Kapur KK, Singh SP, Shankar K, Sinha JN, Kohli RP. Mechanism of cardiovascular action of Terminalia arjuna. Planta Med 1982;45:102-4.

43. Dwivedi S, Chansouria JP, Somani PN, Udupa KN. Influence of certain indigenous drugs on the PGE like activity in the ischaemic rabbit aorta. Indian Drugs 1987;24:378-82.

44. Tandon S, Rastogi R, Kapoor NK. Protection by abana, a herbomineral preparation, against myocardial necrosis in rats induced by isoproterenol. Phytotherapy Res 1996;10:263-5.

45. Gupta LP, Sen SP, Udupa KN. Pharmacological studies on Terminalia arjuna. J Res Indian Med Yoga Homeopathy 1976;11:16-24.
46. Saxena M, Faridi U, Mishra R, Gupta MM, Darokar MP. Cytotoxic agents from Terminalia arjuna. Planta Med 2007;73:1486-90.

47. Halder S, Bharal N, Mediratta PK, Kaur I, Sharma KK. Antiinflammatory, immunomodulatory and antinociceptive activity of Terminalia arjuna Roxb bark powder in mice and rats. Indian J Exp Biol 2009;47:577-83.

48. Kaur SJ, Grover IS, Kumar S. Modulatory effects of a tannin fraction isolated from Terminalia arjuna on the genotoxicity of mutagens in Salmonella typhimurium. Food Chem Toxicol 2000;38:1113-9.

49. Manna P, Sinha M, Sil PC. Protection of arsenic-induced testicular oxidative stress by arjunolic acid. Redox Rep 2008;13:67-77.

50. Chaudhari M, Mengi S. Evaluation of phytoconstituents of Terminalia arjuna for wound healing activity in rats. Phytother Res 2006;20:799-05.

51. Kokkiripati PK, Kamsala RV, Bashyam L, Manthapuram N, Bitla P, Peddada V, et al. Stem-bark of Terminalia arjuna attenuates human monocytic (THP-1) and aortic endothelial cell activation. J Ethnopharmacol 2013;146:456-64.

52. Varghese A, Savai J, Pandita N, Gaud R. In vitro modulatory effects of Terminalia arjuna, arjunic acid, arjunetin and arjungenin on CYP3A4, CYP2D6 and CYP2C9 enzyme activity in human liver microsomes. Toxicol Rep 2015;2:806-16.

53. Gauthaman K, Maulik M, Kumari R, Manchanda SC, Dinda AK, Maulik SK. Effect of chronic treatment with bark of Terminalia arjuna: a study on the isolated ischemic-reperfused rat heart. J Ethnopharmacol 2001;75:197-01.

54. Mandal S, Patra A, Samanta A, Roy S, Mandal A, Mahapatra TD, et al. Analysis of phytochemical profile of Terminalia arjuna bark extract with antioxidative and antimicrobial properties. Asian Pac J Trop Biomed 2013;3:960-6.

55. Bharani A, Ahirwal K, Jain N. Terminalia arjuna reverses impaired endothelial function in chronic smokers. Indian Heart J 2004;56:123-8.

56. Paul S, Ghosh D, Ghosh AK, Bhowmick D, Bandyopadhyay D, Chattopadhyay A. Aqueous bark extract of Terminalia arjuna protects against phenylhydrazine induced oxidative damage in goat red blood cell membrane bound and metabolic enzymes. Int J Pharm Pharm Sci 2016;8:62-70

57. Khalil S. Effect of Statin Versus Terminalia arjuna on Acute Myocardial Infarction (DNB thesis). New Delhi, India: National Board of Examination; 2005

58. Desai SD, Patil BS, Kanthe PS, Potekar RM. Effect of ethanolic extract of Terminalia arjuna on liver functions and histopathology of liver in albino rats fed with hyperlipidemic diet. Int J Pharm Pharm Sci 2015;7:302-6

59. Bharani A, Ganguli A, Bhargava KD. Salutary effect of Terminalia arjuna in patients with severe refractory heart failure. Int J Cardiol 1995;49:191-9.

60. Yaidikar L, Thakur S. Arjunolic acid, a pentacyclic triterpenoidal saponin of Terminalia arjuna bark protects neurons from oxidative stress associated damage in focal cerebral ischemia and reperfusion. Pharmacol Rep 2015;67:890-5. 